\title{
LA APARICIÓN DEL «PROBLEMA DE LA CIRCULACIÓN» Y LOS ORÍGENES DE LA GESTIÓN DEL TRÁFICO URBANO EN ESPAÑA, 1900-1936
}

\section{THE HISTORY OF TRAFFIC CONGESTION AND ITS MANAGEMENT IN SPAIN, 1900-1936}

\author{
Nuria Rodríguez-Martín \\ Universidad del País Vasco/Euskal Herriko Unibertsitatea (España) \\ orcid.org/0000-0003-0179-7392
}

Recibido el 25-5-2016 y aceptado el 15-11-2016

\begin{abstract}
Resumen: A lo largo del primer tercio del siglo xx, Madrid, Barcelona, y en menor medida el resto de capitales de provincia españolas, comenzaron a experimentar una creciente congestión en sus vías públicas. El aumento exponencial del número de vehículos - particularmente de vehículos automóviles -, el incremento del tráfico peatonal - derivado del crecimiento demográfico-, y la existencia de trazados urbanos incapaces de absorber las nuevas corrientes circulatorias, tuvieron como consecuencia la aparición de lo que en la época se denominó «el problema de la circulación». Las autoridades locales lo afrontaron adoptando distintas medidas con las que se inauguró la gestión del tráfico urbano en España, asunto que ha sido escasamente atendido hasta la fecha por la historiografía urbana centrada en este periodo. Este artículo analiza esas primeras medidas, comparándolas con las que por esos mismos años implementaron otras grandes ciudades y capitales occidentales. Se exponen igualmente los primeros intentos para unificar todos los aspectos referentes al tráfico en el territorio nacional, sustanciados en la celebración, en 1933, del Primer Congreso Municipal de Circulación.
\end{abstract}

Palabras clave: regulación del tráfico, congestión viaria, circulación, tracción de sangre, automóviles, señales de tráfico. 


\begin{abstract}
Throughout the first third of the twentieth century, Madrid, Barcelona, and others Spanish cities experienced an increase in traffic problems, including traffic congestion and traffic accidents. The growth of number of vehicles - particularly motorcars - , the increase of pedestrian traffic, and the narrow urban layouts at the central areas of most of the cities, resulted in the socalled at the time «problema de la circulación». Municipal leaders dealt with the problem implementing different measures which inaugurated the history of traffic management in Spain, an issue largely neglected by scholars in Spanish urban studies. Adopting a comparative perspective, this essay examines those measures, including first attempts to unify traffic rules within the country. The paper addresses public discourses and debates over urban mobility, safety and modernization. The research is based on a wide range of sources, including local government reports, newspapers, magazines and photographs.
\end{abstract}

Keywords: traffic management, traffic congestion, horse-drawn vehicles, motor vehicles, traffic control signals. 
El crecimiento de las urbes españolas desde finales del siglo XIX, la implantación y expansión de los transportes urbanos, y la irrupción de los automóviles en las primeras décadas del siglo Xx, dieron lugar a la aparición de un nuevo problema urbano asociado por los contemporáneos a la modernización de las ciudades, el de la congestión circulatoria. Al comenzar los años veinte, este problema era ya una realidad preocupante en los grandes municipios del país, como Madrid y Barcelona, cuyas autoridades se vieron en la necesidad de acometerlo, adoptando para ello diversas medidas, como la formación de personal especializado, el uso de nuevas tecnologías, la aprobación de reglamentos del tráfico, etc. A mediados de los años treinta, otras capitales de provincia y ciudades de tamaño medio, comenzaron igualmente a experimentar lo que en la época se denominó «el problema de la circulación». El número de vehículos que transitaban por sus calles había experimentado un considerable aumento, y aunque no alcanzaba las cifras de Madrid o Barcelona, el trazado urbano de la mayor parte de las ciudades españolas comprendía calles centrales cuya anchura era insuficiente para acoger las nuevas corrientes circulatorias. Una situación expuesta de forma muy expresiva por la ponencia presentada a discusión por la delegación de Barcelona en el primer Congreso Municipal de Circulación, celebrado en Madrid en enero de 1933:

"¿Qué habría de acontecer a aquellos estrechos senderos, caminos, callejuelas y luego, la mayoría de las veces, calles de nuestras ciudades, no superiores ni en mucho a los ocho metros de calzada, cuando en un periodo tan corto como el que media entre 1910 y 1930, es decir, en un espacio de tiempo de veinte años, pasaron a ser cauce del paso diario de 20,30 o 50.000 automóviles, además de otros tantos vehículos de tracción animal, carretones, bicicletas y tranvías? ¿Cuál tenía que ser el resultado? Evidentemente, el caos.

Y nos encontramos tan sólo en la génesis del problema. Dentro de diez años ¿qué sucederá?»» ${ }^{\text {. }}$.

El Congreso Municipal de Circulación, organizado por iniciativa del concejal delegado del Tráfico en el Ayuntamiento de Madrid, Fabián Talanquer, tuvo entre sus objetivos principales, precisamente, adelantarse a lo que se preveía iba a convertirse en uno de los principales retos para las municipalidades españolas, la gestión del tráfico urbano. Un asunto que a pesar de la importancia que adquirió en las agendas locales de las grandes ciu-

\footnotetext{
1 Primer congreso municipal de circulación..., 1933, p. 44.
} 
dades españolas durante el primer tercio del siglo $\mathrm{xx}$, ha sido escasamente atendido por la historiografía social y urbana española centrada en este periodo. Este artículo pretende ser una contribución al campo de la Historia de la movilidad urbana, a través del estudio de los orígenes de los problemas circulatorios en España durante el primer tercio del siglo XX, vinculados a la incipiente motorización experimentada por los principales núcleos urbanos del país en ese periodo, así como de las primeras medidas adoptadas para tratar de corregirlos. Partimos de que estos problemas tuvieron unas dimensiones distintas en función del tamaño, desarrollo y características de cada ciudad, si bien, el examen de las actuaciones implantadas por las municipalidades, revela que éstas fueron, sorprendentemente, muy similares. De este modo, lo que en principio se reveló como una problemática de carácter local, adquirió una dimensión nacional, e incluso global, puesto que la ordenación del tráfico viario, así como los debates públicos sobre la organización del espacio urbano, tuvieron unas connotaciones comunes en todo el mundo urbano occidental. Adoptando una perspectiva comparada, se estudia en el primer apartado la aparición de la congestión viaria en las ciudades españolas durante los primeros años del siglo XX, así como su conceptualización como nuevo problema urbano, a partir de las percepciones sobre el mismo reflejadas en las fuentes documentales ${ }^{2}$. Se exponen, en segundo lugar, las medidas y actuaciones diseñadas por las autoridades municipales para gestionar la congestión circulatoria, para, finalmente, analizar el significado y alcance del primer Congreso Municipal de Circulación celebrado en España en 1933. La investigación se realiza a partir del análisis de una multiplicidad de fuentes documentales, incluyendo expedientes inéditos procedentes de archivos locales, memorias, informes y anuarios del periodo, revistas generalistas y especializadas, periódicos y fotografías de época.

\section{Las primeras manifestaciones del «problema de la circulación» en España}

En las últimas décadas del siglo XIX, la congestión viaria hizo su aparición como un nuevo elemento en la vida cotidiana de las grandes urbes

2 Sobre las percepciones y los discursos en torno a la congestión viaria como «problema urbano» desde finales del siglo XIX, debe verse Weinstein, 2006, quien analiza estas cuestiones tomando como caso de estudio la ciudad de Boston. Asimismo, Pooley y Turnbull, 2005. 
occidentales. El crecimiento demográfico de las ciudades y la multiplicación del número de vehículos en circulación, hicieron que en algunas vías públicas y en distintas horas del día, los desplazamientos de personas y vehículos se efectuaran de forma cada vez más penosa. Las grandes metrópolis europeas del momento, París y Londres, fueron las primeras en experimentar las complicaciones de la circulación en sus vías públicas, y las primeras en verse por ello obligadas a implantar medidas para tratar de atajar o al menos aliviar el problema. En fecha tan temprana como 1868, la capital británica implantó una primera señal luminosa en Westminster para regular el tráfico en la zona ${ }^{3}$. La tracción mecánica que temprana y velozmente se extendió por ambas ciudades aumentó exponencialmente la congestión circulatoria ${ }^{4}$. En París, el número de vehículos de todo tipo en circulación en 1891 era de 45.085, en 1910, 430.0005. Ese mismo año, un informe elaborado por una Comisión municipal encargada de estudiar la circulación de vehículos y peatones en la capital del Sena, reconocía abiertamente que aquélla «dejaba mucho que desear», y que a veces era «intolerable» ${ }^{6}$. En 1903 transitaban por la capital londinense, entre otros vehículos, 13 autobuses, 11.404 coches de alquiler y 3.263 ómnibus de tracción animal. Cinco años después se habían sumado a los vehículos de sangre para el transporte de pasajeros, 2.805 automóviles taxímetros, mientras que el número de autobuses ascendía a $1.133^{7}$.

A lo largo del primer tercio del siglo XX, como consecuencia de la expansión de las redes de transporte urbano y de la irrupción de los vehículos automóviles, salidos ya de las cadenas de montaje de las grandes empresas automovilísticas como Ford, Citroën o General Motors, el problema se multiplicó, adquiriendo una dimensión global. España no permaneció al margen de este proceso, y pronto los principales núcleos urbanos del país se encontraron con sus calles abarrotadas de transeúntes, tranvías, ómnibus, autos, camiones, carros, bicicletas, coches de caballos, etc., que competían por el uso de las vías públicas. El caso de Madrid es significativo a este respecto. Durante el primer tercio del siglo XX la capital de España pasó de ser una ciudad que sus habitantes podían abarcar a

3 Winter, 1993.

4 Flonneau, 2003.

5 Conseil Municipal de Paris, 1910,p. 10.

${ }^{6}$ Conseil Municipal de Paris, 1910, pp. 12-13.

7 Cifras ofrecidas por la revista The Motor reproducidas en Conseil Municipal de Paris, 1910, pp. 12-13. 


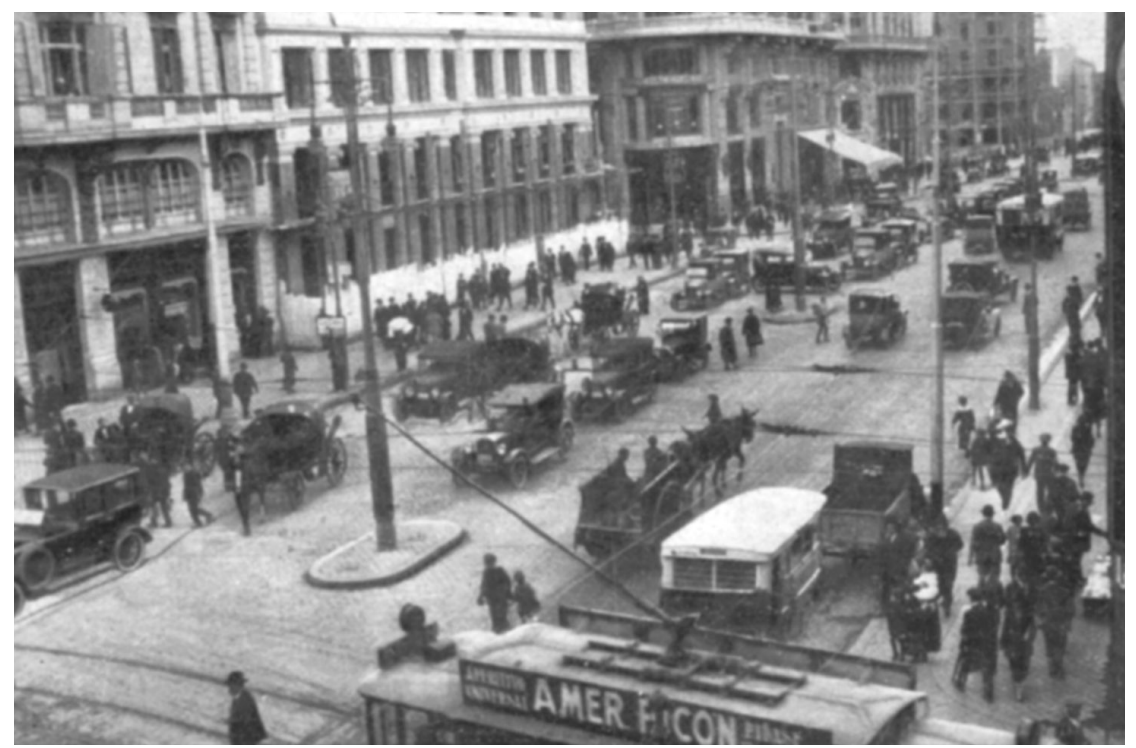

Figura 1

La calle Gran Vía de Madrid a mediados de los años veinte.

La fotografía recoge la distinta composición del tráfico de la ciudad en esos años.

En ella se aprecian varios coches de caballos, carros de sangre y camionetas, dos autobuses, un tranvía eléctrico y numerosos automóviles

Fuente: Nuevo Mundo, 20 de febrero de 1925. Biblioteca Digital Memoria de Madrid

pie - una walking city - , para transformarse en una urbe organizada sobre una extensa red de transportes y una oferta masiva de todo tipo de vehículos de uso público ${ }^{8}$. Al comenzar el siglo XX la capital de España contaba con una importante red tranviaria que se extendía por toda la ciudad, sus barrios periféricos y municipios limítrofes ${ }^{9}$. En 1906 la estadística municipal estimaba que junto a los tranvías, circulaban por la ciudad unos 5.000 vehículos más, la mayoría carros y coches de tracción de sangre, aunque ya se consignaban cerca de 500 automóviles, tanto de uso pú-

\footnotetext{
8 Rodríguez, 2015; González, 2006.

9 Gutiérrez, 1983; López, 1993.
} 
blico como particular. Las cifras, aunque importantes, eran todavía modestas si las comparamos con las registradas para el año 1929: cerca de 32.000 vehículos rodando por las vías públicas de la capital, lo que significa que en apenas veinte años se había sextuplicado ${ }^{10}$.

En este periodo además, la composición del tráfico urbano se modificó radicalmente. La tracción de sangre desapareció casi por completo, arrollada por el motor de explosión y por la electricidad en el caso de los tranvías (Gráfico 1). Un proceso bien ilustrado por lo sucedido con la Sociedad de Alquiladores de Carruajes, órgano que asociaba a la mayor parte de los industriales dedicados al negocio del alquiler de coches de sangre en Madrid desde 1897, año de su constitución. En 1900 la So-

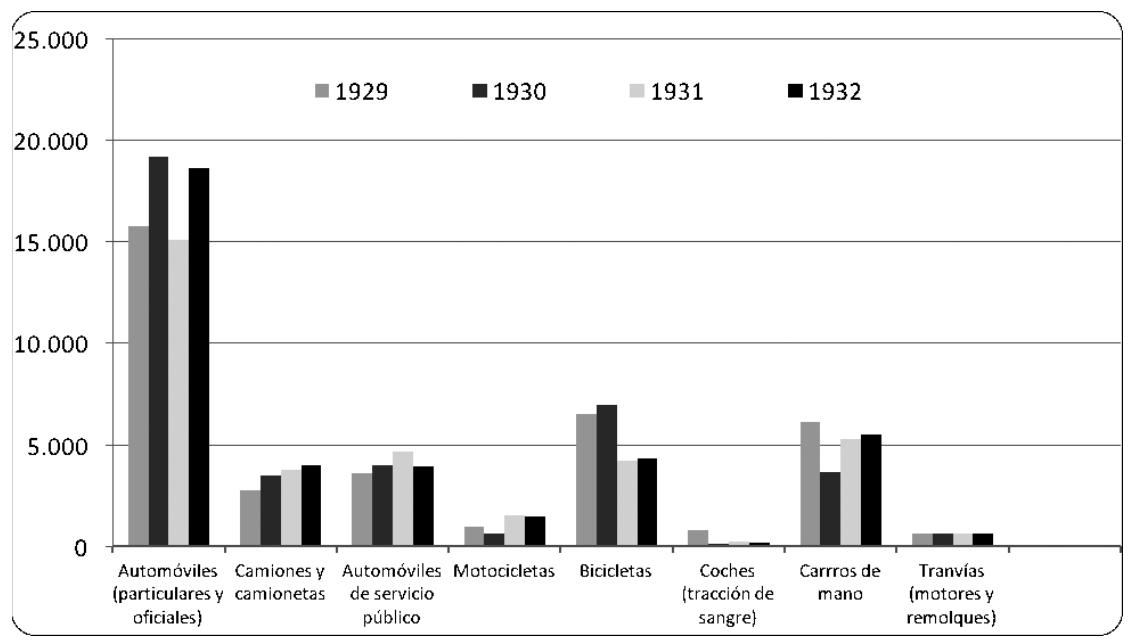

\section{Gráfico 1}

Composición del tráfico en Madrid por tipo de vehículos en los años indicados

Fuente: Elaboración propia a partir de datos recogidos en Memoria de Circulación por José de la Hoz Muñoz. Jefe accidental de la Compañía de Circulación. Ayuntamiento de Madrid. Año 1932

10 Datos del Negociado de Estadística del Ayuntamiento de Madrid reproducidos en la revista Transporte. Órgano de la Unión General de Obreros del Transporte, 17 (septiembre de 1930). 
ciedad tenía registrados 2.500 caballos, en 1929, solo 217. Tan rápida fue la decadencia de este sector que en 1932, una instancia del presidente de la Sociedad dirigida a la alcaldía, en la que solicitaba reducir el canon que anualmente se abonaba al Ayuntamiento, recogía que solo subsistían ya 76 caballos, explicando que «Por el número citado, puede V.E. considerar el estado de agotamiento a que hemos llegado, cosa nada de extrañar, ya que nadie alquila un carruaje de esta clase, para abono, y por el contrario, las pocas personas que los utilizan (casi todas ancianas), unas lo abandonan para disfrutar otros elementos más modernos, y otras dejan el servicio por cuestión económica» ${ }^{11}$. La prensa del momento reflejó a través de numerosos reportajes y caricaturas, y de forma más emotiva que mordaz, la desaparición de las bestias de las calles de la ciudad arrolladas por el neumático y la gasolina ${ }^{12}$. Al fin y al cabo, los coches de caballos eran representantes de una época, del mundo de ayer de las ciudades, mientras los automóviles de brillantes carrocerías eran uno de los más llamativos símbolos de la nueva sociedad surgida tras la Gran Guerra, que los abrazó como emblema del progreso y la modernidad ${ }^{13}$.

Los datos expuestos para Madrid son muy similares a los que ofrecía la otra gran urbe del país, Barcelona. Al comenzar el año 1929, la Ciudad Condal tenía matriculados 20.278 vehículos automóviles (particulares, taxis y camiones), además de 4.415 carros y 8.229 bicicletas $^{14}$. También se había multiplicado exponencialmente la circulación de transeúntes por las vías públicas, dados los incrementos de población que registraron ambas ciudades. Los censos nacionales consignan 539.835 habitantes en Madrid en el año 1900, 952.832 en 1930. En el caso de Barcelona, 533.000 y 1.005 .565 respectivamente para los mismos años ${ }^{15}$. El primer estudio

11 A.V.M., Secretaría, expediente 12-391*-58.

12 Como ejemplo, «El imperio del «taxi» y la agonía del coche simón», en El Sol, 13 de febrero de 1924; «Conmovedor centenario de los «simones»», en $A B C, 26$ de febrero de 1935; «¿Quiere taxi?», en Mundo Gráfico, 15 de mayo de 1935; Luis Blanco Soria, «Episodios de la vida de un viejo «simón»», en $L a$ Voz, 8 de marzo de 1930.

${ }^{13}$ Frente a la interpretación más aceptada y difundida por la historiografía que vincula la expansión del automóvil en el mundo como una imposición por parte de grupos de presión y élites políticas y económicas, Mathieu Flonneau ha argumentado, estudiando el caso de París, la gran aceptación de este tipo de vehículos, al menos hasta los años 70, entre la sociedad metropolitana. Véase Flonneau, 2006.

${ }^{14}$ Datos distribuidos a la prensa por el Consejero regidor de Política Social y Estadística, reproducidos en La Vanguardia, 20 de agosto de 1935.

15 Censos de Población de España, años 1900 y 1930, Instituto Nacional de Estadística. 


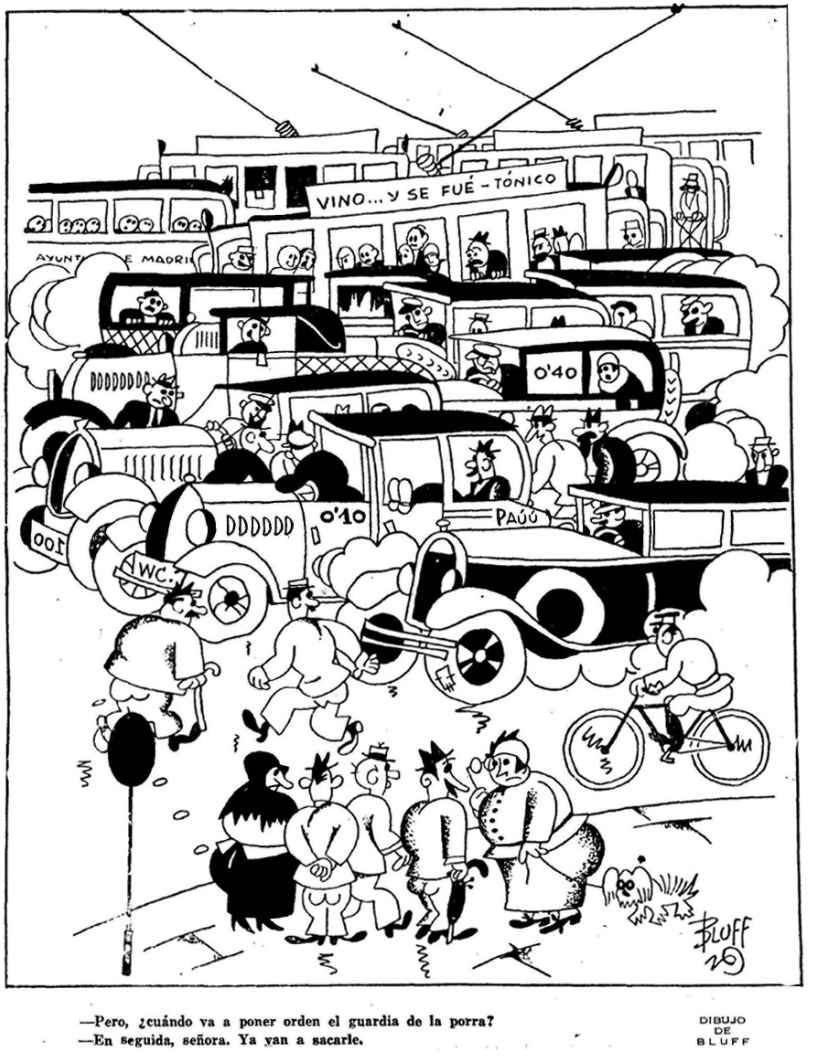

Figura 2

Caricatura publicada en la revista satírica Gutiérrez que se burla del caos circulatorio en Madrid

Fuente: Gutiérrez, 3 de agosto de 1929. Fondos de la BNE

sobre volumen y desplazamientos de peatones en Madrid, realizado en 1926, estableció un promedio diario de medio millón de viandantes en la ciudad. Los datos estaban basados en observaciones realizadas en distintas horas de días tanto festivos como laborables, pero referidos solo a una jornada de ocho horas, por lo que solo representaban una parte del número - si bien fabuloso - de transeúntes en las principales calles y plazas de la 
ciudad $^{16}$. La intensidad del tráfico peatonal en Madrid no dejó de aumentar y al mismo tiempo, de adaptarse a los ritmos de la vida moderna. En 1932, una detallada Memoria redactada por el Jefe de la Compañía de Circulación del Ayuntamiento, José de la Hoz Muñoz, ofrece, además de abundantes datos de la organización del tráfico, una viva imagen de la vida cotidiana en el Madrid de los años treinta. Una ciudad que nada tenía que ver con la urbe decimonónica retratada por Benito Pérez Galdós. Una ciudad con ritmos frenéticos donde se imponían nuevos usos y costumbres característicos de la Modernidad. Así lo recoge en su descripción de la circulación diaria de peatones, en la que se observaban varias corrientes de gran intensidad en coincidencia con las nuevas formas de trabajo y diversión, y que se transcribe íntegra por su gran expresividad:

«la primera [corriente circulatoria] de 7'30 a 9; entrada al trabajo y oficinas. No influye en la circulación de vehículos ligeros y solo son utilizados los de transporte en conjunto: tranvías y metropolitano.

De 10 a 1, los negocios, las compras, el paseo, lanzan a la calle un crecido número de personas.

A las 2 de la tarde: marcha al hogar para hacer la comida; no es tan grande como la de la mañana por comer muchos obreros en el taller o en el tajo.

De 3 a 4, vuelta otra vez al trabajo; de intensidad análoga a la anterior.

$\mathrm{Y}$ a las 5 empieza una oleada gigantesca que invade las calles y se dirige en interminable peregrinación a la Puerta del Sol, Gran Vía, calles de la Montera, Mayor, Alcalá y Carrera de San Jerónimo, y utilizan para su transporte toda clase de vehículos, aunque una enorme cantidad gusta de marchar a pie. Esta ola humana, empieza su retirada de 8 a 9 , siendo esta la última y más importante corriente circulatoria de peatones» ${ }^{17}$.

Como puede advertirse, unos ritmos urbanos en gran medida muy similares a los que la ciudad sigue experimentando en la actualidad. No obstante, y a pesar de ser el volumen de peatones y vehículos en determinados puntos y horarios el principal factor de la congestión circulatoria, el trazado urbano era también causa importante de la misma. Los princi-

\footnotetext{
16 Abarca, 1926.

17 Memoria de Circulación, 1932, p. 81.
} 
pales puntos de congestión se situaban en el núcleo central de la ciudad. Los defectuosos enlaces entre las tres grandes zonas en las que se encontraba dividido Madrid eran en gran medida responsables del problema, con un núcleo central de calles caracterizadas por su estrechez, un Ensanche planificado según el sistema reticular o cuadrangular, y un Extrarradio que estaba aún en su mayor parte sin urbanizar a la altura de los años treinta ${ }^{18}$. Los principales nudos de circulación de la ciudad se localizaban en el centro de la misma, en la Puerta del Sol y sus calles adyacentes, plazas de Cibeles, de Callao y de Santo Domingo, el encuentro de la calle Gran Vía con la de Alcalá, la Red de San Luis (Gran Vía), calle de Sevilla y Glorieta de Atocha ${ }^{19}$. La Puerta del Sol y las calles de Alcalá y Gran Vía eran también los lugares donde los embotellamientos eran más habituales, la enorme afluencia de vehículos y transeúntes que soportaban se debía al hecho de ser la principal área comercial de la ciudad, donde además se localizaban el mayor número de locales de ocio y restauración (cinematógrafos, teatros, bares, cafés, salas de espectáculos, frontones, restaurantes, etc., etc.) y la mayoría de oficinas y centros oficiale ${ }^{20}$. La maraña circulatoria en la zona se complicaba aún más por concentrarse en ella el núcleo de la red tranviaria madrileña, particularmente en la Puerta del Sol, lo que convertía a la plaza, en opinión del director municipal del tráfico en «un cocherón intransitable» ${ }^{21}$, quien censuraba que:

«La Compañía de Tranvías no lanza un coche a la calle o implanta una nueva línea sin que forzosamente tenga su paso o haga su parada en la Puerta del Sol, sin que esto reporte beneficio a la Empresa ni a los viajeros. Es vergonzoso por esta causa ver la calle de Alcalá formada con un tren de tranvías que las más de las veces llega hasta la Cibeles; si a estos coches se les hiciera, como marcan las Ordenanzas, guardar entre uno y otro una distancia no inferior a 20 metros, la Compañía tendría que hacer una vía supletoria en la carretera de Aragón, puesto que los tranvías rebasarían con creces el término municipal» ${ }^{22}$.

18 Ayuntamiento de Madrid, s. d. [1929].

19 Paz, 1933, pp. 49-50; Memoria de Circulación..., pp. 83ss.

20 Sobre el centro de Madrid y la calle Gran Vía como distrito financiero y de ocio de la ciudad, véase, Baker, 2009, y De Miguel, 2016.

21 Ayuntamiento de Madrid, 1924, p. 7.

22 Ibid., p. 7. 
En los años veinte, París y Londres habían retirado de sus áreas centrales los tranvías para mejorar la circulación, pues la rigidez de la trayectoria de este tipo de vehículos se veía como un obstáculo para el tráfico, frente a transportes más flexibles, como los autobuses, que podían modificar sus trayectorias en caso de necesidad. En otras muchas ciudades europeas, y a pesar de ser el tranvía un vehículo público de uso enormemente popular, surgían cada vez más voces críticas contra él. No sólo por su nula flexibilidad, sino también por considerársele anticuado y poco acorde con la ciudad moderna ${ }^{23}$.

Las autoridades locales madrileñas intentaron, con escaso éxito, descongestionar el tráfico tranviario del núcleo central de la ciudad. Un proyecto que respaldaba una gran parte de la opinión pública, como recogen numerosos editoriales, cartas al director y artículos publicados por los diarios. Sin embargo, otros motivos pueden hallarse tras la lucha emprendida por las autoridades locales contra el tranvía en el centro urbano, pues en esa época fueron frecuentes los conflictos y hostilidades entre la Sociedad Madrileña de Tranvías (SMT) por un lado, y el Ayuntamiento y los vecinos de Madrid por otro. Detrás de esas disputas estaban las tarifas de los billetes y las faltas e incumplimientos en el servicio por parte de la SMT (horarios, frecuencia y número de coches por línea, etc.), y asimismo el hecho de que los tranvías fueran además responsables de constantes accidentes en la vía pública, particularmente de atropellos de transeúntes, lo que no hacía sino alimentar la antipatía del público hacia la compañía de transportes. De forma mucho más interesada, las asociaciones automovilistas de Madrid realizaron una constante campaña desde sus órganos de expresión contra el tranvía, campaña a la que se sumaron las organizaciones obreras y sindicales que afiliaban a los obreros del transporte ${ }^{24}$. Como

${ }^{23}$ Pooley y Turnbull, 2005, pp. 83ss. Los autores reconstruyen en su artículo los conflictos entre transporte público y privado por el control del espacio público en Glasgow y Manchester entre las décadas de 1920 y 1950, en el contexto de la multiplicación de la congestión y los problemas del tráfico en ambas ciudades.

${ }^{24}$ Como ejemplos de la campaña a favor de la supresión de los tranvías en el centro de Madrid, véase, entre otros, Ignacio de León y P. de Rivera, «El problema de la circulación de vehículos en Madrid y la reversión de los tranvías al municipio I y II», en España automóvil y aeronáutica, $\mathrm{n} .^{\circ} 8$ y n. 9 (1925), p. 123 y pp. 141 y 145; también Adolfo Hinojar, «La circulación urbana en Madrid», en Madrid Automóvil (enero de 1933), pp. 19 y 21; y «El problema de la circulación en Madrid», en Heraldo Deportivo, 25 de marzo de 1930, pp. 110-112. 
ejemplo de esta postura, un artículo publicado en 1934 en Fuerza, revista del sindicato UGT, sostenía que:

«La circulación de tranvías en Madrid, que constituye la pesadilla de cuantos organismos y particulares se interesan por ello, no tiene solución con pequeñas reformas [...]; este problema hay que abordarlo de frente y con valentía, suprimiendo totalmente la circulación de esta clase de vehículos en una zona lo más extensa posible del centro de la ciudad. Ya sabemos, o nos figuramos, que a usted [Sr. Buceta, delegado del Tráfico del Ayuntamiento] no le es posible, porque no entra en su formación burguesa, despojar a la Compañía de Tranvías de parte de unas concesiones que usted y ella reputarán legítimas; pero cuando las concesiones están en pugna con el interés general, como sucede con éstas, deben declararse inmediatamente caducadas $»^{25}$.

También en Barcelona esta cuestión fue ampliamente discutida por las autoridades municipales y otros expertos en la materia, que planteaban suprimir los tranvías en lugares céntricos como las Ramblas, aunque tampoco en la Ciudad Condal lograron avanzar en esta cuestión ${ }^{26}$. En 1933, durante una acalorada sesión municipal en la que se debatía sobre las líneas de autobuses urbanos, el concejal responsable del Tráfico, Jaume Vachier, defendía la postura del Ayuntamiento recordando que en todas las grandes capitales habían sido suprimidos los tranvías, reemplazados por los autobuses, a los que expresivamente calificaba como «el vehículo indispensable del porvenir» 27 .

La necesidad de armonizar los proyectos de reforma urbana con la exigencia de hacer más fluida la circulación de vehículos en las ciudades, se convirtió en el primer tercio del siglo XX en una preocupación para las autoridades locales de Madrid y Barcelona, de igual forma que sucedía en el resto de capitales occidentales, particularmente cuando comenzaron a calcularse los enormes costes que para las economías urbanas tenía una deficiente circulación viaria. Esta preocupación está presente, por ejemplo, en el Plan General de Extensión para Madrid aprobado por el Ayuntamiento en el año 1926, donde se dedicaba gran atención a los transpor-

25 «La reforma de la circulación en Madrid», en Fuerza. Órgano mensual de la Federación del Transporte en España, n. 29 (1 de agosto de 1934), p. 5.

${ }^{26}$ Ernesto Ramis Matas, «Un plan para disminuir el paro obrero en Barcelona», en $L a$ Vanguardia, 25 de febrero de 1933.

27 «Las nuevas líneas de autobuses», en La Vanguardia, 24 de septiembre de 1933. 
tes y a la organización del tráfico de vehículos y personas en la ciudad ${ }^{28}$. También en los proyectos de reforma de la capital de España del arquitecto Secundino Zuazo a comienzos de los años treinta, que incorporaban, por ejemplo, la creación de nuevas arterias de tráfico para descongestionar la zona central de la ciudad ${ }^{29}$. Por las mismas fechas, el Colegio de Arquitectos de Barcelona se dirigía públicamente a la alcaldía de la ciudad a través de la prensa, reclamándole fijar una «política del tráfico», que considerara el problema del transporte como «esencial e indispensable para dotar de una acertada "política urbanística" a la ciudad» ${ }^{30}$.

$\mathrm{Al}$ exponer la creciente congestión circulatoria y su organización, deben considerarse, al menos, tres factores más. El primero es la multiplicación de «obstáculos» en las vías públicas, que reducían el espacio disponible para el tránsito, tanto en las aceras como en las calzadas, esto es, distinto mobiliario urbano instalado en las calles de las ciudades. El aumento de los servicios públicos y la creciente complejidad de la vida urbana motivaron la multiplicación de artefactos en las vías públicas, tales como buzones de correos, postes telefónicos, columnas y apeaderos de los tranvías, paradas de autobuses, marquesinas del ferrocarril subterráneo, aparatos para hacer publicidad en las vías públicas, como carteleras, columnas y farolas anunciadoras, kioscos, pequeños puestos de venta callejera, terrazas y veladores de hostelería y restauración, farolas del alumbrado público, papeleras, etc. ${ }^{31}$. Asimismo, los propios objetos para la organización y las nuevas necesidades del tráfico, como las señales indicadoras, los semáforos, los refugios para peatones y otros elementos como los surtidores de gasolina, y los aparatos para hinchado de neumá-

28 Plan General de extensión, 1926, pp. 28-29.

29 Véase a este respecto, Secundino Zuazo, «El Madrid futuro. Un gran plan de reformas», en El Sol, 17 de enero de 1932 y El Sol, 31 de enero de 1932.

${ }^{30}$ La Vanguardia, 21 de octubre de 1931.

${ }^{31}$ El Ayuntamiento de Madrid remitía de forma habitual comunicaciones a organismos públicos y privados, solicitando la supresión de elementos de la vía pública por ser un obstáculo para el tráfico urbano, además de denegar frecuentemente las instancias que recibía de particulares para realizar publicidad en las calles, particularmente de publicidad móvil, por ser este tipo de anuncios un impedimento a la circulación de vehículos y peatones. Rodríguez, 2016. A.V.M., Secretaría, Expediente 21-112-62 promovido por el Sr. Teniente de Alcalde del Distrito de Congreso interesando el levantamiento de los kioskos instalados en la plaza de Antón Martín. 1905. A.V.M., Secretaría, Expediente 29-392-31 relativo a relación remitida por el Sr. Gestor Delegado de Circulación de buzones de Correos que por hallarse situados en calles declaradas congestionadas procede que desaparezcan. 1935. 
ticos, etc. ${ }^{32}$. Si a ello le sumamos los obstáculos derivados de los muchos trabajos de construcción y reforma que se acometieron en las ciudades en aquellos años, se entiende la exasperación que transmiten muchos de los informes y escritos de los ingenieros y técnicos de las distintas secciones municipales implicadas en la organización del tránsito rodado.

En segundo lugar, los propios vehículos eran en sí mismos un obstáculo para la circulación cuando se encontraban estacionados en las calzadas, particularmente los automóviles, de ahí que comenzaran a estudiarse soluciones para su acomodo en la ciudad, planteándose la construcción de grandes aparcamientos. En los años veinte la prensa madrileña denunciaba que las calles aparecían a determinadas horas del día convertidas en «inmensos garajes, que ocupan espacios que son indispensables para atender a las necesidades del tránsito rodado» ${ }^{33}$. El crecimiento del parque automovilístico madrileño no hizo sino agravar el problema. El director de la Compañía de Circulación del Ayuntamiento denunciaba en la Memoria referente al año 1932 que:

«Esta necesidad [de estacionar], que cada día se agrava más por el aumento constante de vehículos, no ha merecido la atención de que debe ser objeto tan interesante aspecto de la circulación; se construyen edificios enormes que se llena de cafés, hoteles, oficinas y otros lugares de reunión y no se cuida de dejar espacios libres apropiados para el estacionamiento de carruajes [...] En los proyectos viarios de la Capital no se tiene jamás en cuenta este importante detalle del estacionamiento que está íntimamente ligado con el de la circulación, de la que es complemento obligado, y por no afrontar el problema en detalle y adelantándose a la necesidad habrá que hacerlo algún día más en grande y por procedimientos más onerosos, tales como el derribo de algunas manzanas de casas o construcciones de garajes subterráneos, cosas que realmente no son ya una novedad» ${ }^{34}$.

Las numerosas líneas de autobuses que unían las principales capitales de provincia con Madrid, así como las líneas de autobuses suburbanos que conectaban la capital con sus barriadas y pueblos limítrofes - cerca de treinta en $1933^{35}$ - eran igualmente un elemento que añadía no po-

\footnotetext{
32 Real Automóvil Club de España, 1928. Ayuntamiento de Madrid, 1925.

33 El Imparcial, 11 de enero de 1929.

${ }^{34}$ Memoria de Circulación..., 1932, pp. 51-53.

35 A.V.M., Secretaría, expediente 29-59-33.
} 
cas complicaciones a la circulación en la ciudad. Lo que llevó al Consistorio a estudiar distintos proyectos para la construcción de una gran estación central de autobuses, que no llegaron a materializarse ${ }^{36}$. No obstante, y dado que tanto el número como el tamaño de estos vehículos eran un estorbo constante para el tráfico en el área central de Madrid, se adoptaron algunas importantes medidas ${ }^{37}$. La más ambiciosa fue el plan de retirar los autobuses hacia calles apartadas del centro, pero bien comunicadas con paradas de tranvía y estaciones de Metro, y el establecimiento de un perímetro dentro del área central de la ciudad en el que no podrían estacionarse los autobuses, ya fueran de carácter interurbano, suburbano o de carácter privado ${ }^{38}$.

Finalmente, un tercer elemento a considerar cuando se trata de analizar la creciente complejidad de la organización del tráfico urbano, fue el hecho de que las calles eran escenario de celebraciones de grandes manifestaciones de todo tipo, ya fueran de carácter político, religioso, deportivo, etc., que modificaban los flujos circulatorios, poniendo a prueba a los responsables locales del tráfico. En el caso de Madrid ésta fue una cuestión de verdadera importancia, dada su condición de capital del Estado. En los años treinta, encauzar el movimiento de grandes masas tanto de vehículos como de peatones se había convertido en una actividad casi cotidiana para los agentes de la circulación. Partidos de fútbol, corridas de toros, manifestaciones y mítines políticos, entierros de personalidades, procesiones y fiestas religiosas como el Día de Todos los Santos o el Corpus Christi, congregaban a miles de personas en determinados puntos y horas concretas, y suponían un reto añadido al trabajo cotidiano de los

36 Marcos Sylva, «Madrid necesita una gran Estación Central de autobuses de línea», en Nuevo Mundo, 22 de abril de 1932; Expediente a instancia de José López Izquierdo [...] solicitando construir estaciones de autobuses. 1930. Este proyecto incluía la construcción de una gran estación en las proximidades de las estaciones ferroviarias del Norte y de Atocha, para autobuses de línea. Fue favorablemente informado por el Arquitecto Municipal, «pues es evidente que el estacionamiento de autobuses constituye hoy un grave problema de circulación, que habrá de agravarse más cada día; y no parece mal enfocada la solución en la forma en que este expediente se propone...». A.V.M., Secretaría, expediente 29-59-4.

37 Ya en 1930 el director de la Oficina del Tráfico de Madrid, Emilio Abarca, expresaba la preocupación de su departamento por esta cuestión, y manifestaba a la prensa que era necesario «obligar a las Empresas de coches de línea a que, como ocurre en otras poblaciones europeas, arranquen de las afueras.». Entrevista a Emilio Abarca en «Un rato a coches en la Inspección del Tráfico», en $A B C, 12$ de enero de 1930.

38 Marcos Sylva, «Todo Madrid es una inmensa estación de entrada y salida de autobuses», en Nuevo Mundo, 8 de abril de 1932; A.V.M., Secretaría, expediente 29-59-33. 
servicios del Tráfico del Ayuntamiento. En verano, además, los días festivos se producían éxodos masivos de los madrileños hacia la Sierra. Hasta 4.590 vehículos podían salir y regresar a la ciudad en un solo domingo de estío, muchos de ellos autobuses fletados para la ocasión, trasladando, según cálculos de los técnicos municipales, a cerca de 23.000 personas, que abandonaban por un día la urbe buscando el descanso de las faenas de la semana $^{39}$. De este modo, los denominados «servicios extraordinarios» se convirtieron, en la práctica, en una actividad ordinaria para los agentes y directores del Cuerpo de Policía Urbana de Madrid.

Algo similar ocurrió en Barcelona respecto a esta cuestión. En 1928, el jefe de la Guardia Urbana de la ciudad, Manuel Ribé, en una entrevista concedida a la prensa ponía como ejemplo de las complicaciones que debía afrontar el Cuerpo con motivo de las grandes aglomeraciones que periódicamente experimentaba la ciudad y que hacían imprescindible establecer medidas especiales, el combate en el que la estrella del boxeo Paulino Uzcudun ganó su primer Campeonato de Europa en 1926. Jamás se habían visto hasta entonces en Barcelona tantos vehículos reunidos, congregándose en la Plaza de toros Monumental más de 30.000 personas, la mayoría de las cuales se había trasladado allí en auto. Pero según destacaba Ribé, gracias a la previsión y a la adopción de normas circulatorias específicas, lograron despejar la plaza en veinte minutos, localizando fácilmente su coche todo el mundo y sin que se produjeran incidentes ${ }^{40}$.

\section{Las primeras medidas para atajar el «problema de la circulación»}

Dada la magnitud que el problema del tráfico iba adquiriendo, las autoridades locales de ambas ciudades se vieron en la obligación de tomar medidas que lo atajaran, o al menos trataran de paliarlo. En el primer tercio del siglo Xx, el Gobierno aprobó legislación específica relacionada con el tráfico, como los Reglamentos para la circulación de vehículos con motor mecánico por las vías públicas de España de $1918^{41}$

\footnotetext{
39 Memoria de Circulación...,1932.

40 Estampa, 24 de enero de 1928. La Vanguardia, 19 de mayo de 1926.

${ }^{41}$ Reglamento para la circulación de vehículos con motor mecánico por las vías públicas de España, aprobado por Real decreto de 23 de julio de 1918 (publicado en Gaceta de Madrid de 24 de julio de 1918).
} 
y de $1926^{42}$, o el Reglamento de Circulación urbana e interurbana de 1928, además del Código de Circulación de 193443. Pero estas leyes eran generales, razón por la cual los ayuntamientos hubieron de adoptar normas particulares que se adaptaran a la realidad cotidiana de cada ciudad $^{44}$. Además, el Estatuto Municipal de 1924 concedía a los Ayuntamientos competencia exclusiva para «ordenar el uso comunal de la vía pública» (artículo 150). Los mismos Reglamentos nacionales reconocían a los municipios la capacidad para establecer reglas especiales en cada localidad, siempre que respetaran los preceptos generales contenidos en ellos.

Entre las primeras medidas tomadas por las municipalidades para afrontar el problema de la congestión circulatoria, estuvieron la organización de departamentos y la formación de personal especializados en la gestión del tráfico en el interior de las ciudades. En Madrid se creó en junio de 1926 la Dirección General del Tráfico Urbano «para entender en todo aquello que con los problemas de la circulación de vehículos y peatones se relacione» ${ }^{45}$, haciéndose cargo de la misma el segundo jefe de la guardia municipal. A partir de la existente guardia urbana, una especie de policía local actual, se formó desde 1924 una plantilla especializada de agentes encargados de dirigir y encauzar diariamente los flujos circulatorios de Madrid. Estos agentes eran conocidos coloquialmente por los madrileños como los guardias de la porra o los porritas, y eran un cuerpo equivalente al que ya funcionaba en grandes ciudades como París, Londres, o Berlín ${ }^{46}$.

Pronto se convirtieron en un elemento omnipresente en el paisaje urbano de la capital de España, y las escasas críticas publicadas contra su labor en algunos diarios, se transformaron en llamamientos para aumen-

${ }^{42}$ Reglamento para la circulación de vehículos con motor mecánico por las vías públicas de España, aprobado por Real decreto de 16 de junio de 1926, y puesto en vigor en 1. ${ }^{\circ}$ de agosto del mismo año (publicado en Gaceta de Madrid de 19 de junio de 1926). También Anejos y declaraciones al Reglamento de circulación (R.O. de 7 de julio de 1926, 21, 26 de agosto; $15,20,21$ y 22 de septiembre).

${ }^{43}$ Código de Circulación de 25 de septiembre de 1934 (publicado en Gaceta de Madrid de 26 de septiembre de 1934).

44 Véase Cano, 1999.

45 Ayuntamiento de Madrid, 1926.

46 Indalecio Prieto, «El Mausoleo del Congreso y los guardias de la porra», en El Imparcial, 12 de mayo de 1925; «El problema de la circulación en Madrid. Lo que nos ha dicho D. Emilio Abarca», en Unión Patriótica, 1 de marzo de 1927, pp. 13-16. 
tar su número ${ }^{47}$. En los años treinta la Compañía de Circulación de Madrid estaba formada por 5 inspectores, 5 brigadas, 345 guardias a pie y 20 motoristas, cuyos servicios se verificaban en cuatro turnos que cubrían las 24 horas, y en los que se distribuía al personal de acuerdo a las necesidades de la ciudad en las diferentes zonas y momentos del día ${ }^{48}$. En Barcelona también se había creado prontamente, a partir de la guardia municipal, una sección específica para encargarse de la regulación del tráfico.

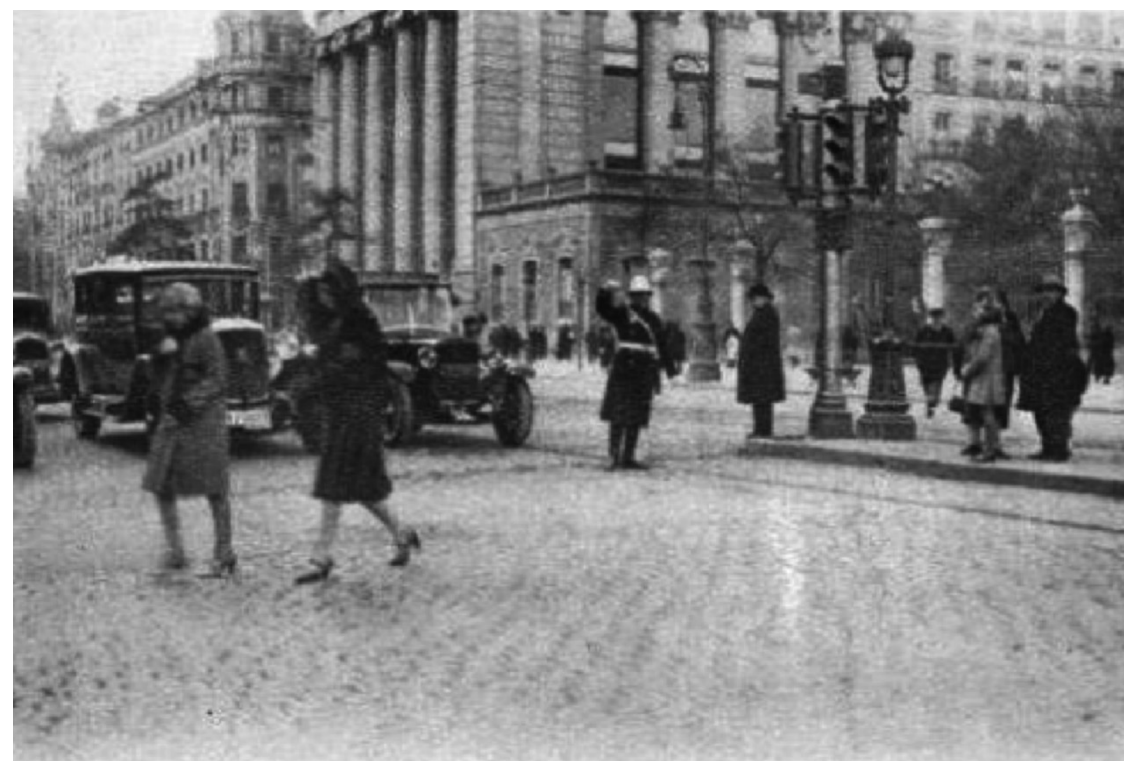

Figura 3

Imagen de la calle de Alcalá al comenzar los años treinta, en la que se aprecian algunos de los elementos adoptados para regular la circulación en Madrid: el guardia urbano, los semáforos y los refugios para peatones instalados en el centro de la calzada

Fuente: Detalle de una tarjeta postal publicitaria digitalizada en la Biblioteca Digital Memoria de Madrid

47 «Hacen falta más guardias de la circulación», en Heraldo de Madrid, 28 de mayo de 1928; «Cincuenta y cinco agentes más de circulación», en El Debate, 2 de marzo de 1928.

${ }^{48}$ Memoria de Circulación... Año 1932..., pp. 1-2. 
En 1928 la Ciudad Condal contaba con 150 guardias urbanos que conformaban la brigada de circulación ${ }^{49}$. En los años treinta, otras ciudades españolas como Valencia, Zaragoza, Bilbao y Palma de Mallorca, contaban igualmente con agentes de la circulación. La capital vizcaína contó incluso con una brigada motorista para la vigilancia del tráfico desde $1935^{50}$.

Además de personal especializado, las ciudades se sirvieron de innovaciones tecnológicas para tratar de mejorar sus problemas circulatorios, como las señales o farolas luminosas, que hoy conocemos como semáforos. Este elemento, concebido en un primer momento para ayudar a los agentes de la circulación en su trabajo de dirigir el tránsito de vehículos y peatones a pie de calle, fue, según Buiter y Staal, una pequeña pero no obstante notable pieza en el desarrollo de la gestión del tráfico ${ }^{51}$. La primera señal luminosa instalada de forma permanente para organizar el tráfico viario se situó en una avenida de Cleveland, Ohio, en 1914. Constaba de dos colores - el rojo y el verde - y era accionada manualmente por agentes de policía. Tres años después, en Detroit, se añadió a este sistema un tercer color, el ámbar, que advertía de un cambio inmediato en la señal. Otras ciudades norteamericanas adoptaron rápidamente esta innovación, y antes de 1920 los semáforos se habían extendido por los Estados Unidos, donde los embotellamientos en los distritos centrales de Boston, San Francisco, Chicago o Nueva York, eran crónicos desde los primeros años del siglo ${ }^{52}$. Madrid fue la primera ciudad española - y una de las primeras en Europa, en instalar una de estas señales luminosas ${ }^{53}-$. Se colocaron las primeras en marzo de 1926 en las calles de Gran Vía y Alcalá, dos de las vías con mayor flujo circulatorio de la ciudad. Hasta ese momento, los guardias de la circulación se encargaban de cortar periódicamente la circulación de vehículos para permitir el cruce de las calzadas por los transeúntes en las calles con mayor tráfico, un sistema que la

49 Entrevista a Manuel Ribé, Jefe de la Guardia Urbana de Barcelona, en Estampa, 24 de enero de 1928.

${ }^{50}$ La Voz, 30 de enero de 1935.

51 Buiter y Staal, 2006, p. 3.

52 Sobre la historia de la regulación semafórica del tráfico viario, la difusión de los semáforos por las principales ciudades de todo el mundo durante los años veinte y treinta, y el proceso de estandarización de este elemento bajo la influencia de los ingenieros norteamericanos, sigue siendo un texto de referencia el de McShane, 1999.

53 Luz ámbar..., 2007. 
prensa había denunciado repetidamente como ineficaz, reclamando uno más regular, como el que ofrecían los modernos semáforos:

«Al iniciarse la organización del tránsito rodado y de peatones anunciamos que algún día, por la forma en que los guardias cortaban la circulación de carruajes y la reanudaban, ocurriría una desgracia, pues echaban de improviso sobre los confiados peatones que cruzaban la calzada, al amparo del funcionario municipal, una verdadera tromba de automóviles. El suceso ocurrió días pasados en la Gran Vía. Para evitar esto; para hacer regulada la parada, que debía producirse a un tiempo en todos los trayectos para impedir aglomeraciones más peligrosas que la circulación libre, pedíamos que se hiciese una instalación de farolas luminosas $[\ldots]^{54} \gg$.

Para ayudar al público a entender y obedecer las señales, el Ayuntamiento redactó unas instrucciones que distribuyó entre los conductores y dueños de automóviles, contando para ello con la colaboración del RACE, además de solicitar a los diarios de Madrid que reprodujeran el significado del sistema de colores, y las indicaciones para efectuar los cruces ${ }^{55}$. A lo largo de varias semanas, los madrileños fueron informados sobre el significado e interpretación de las señales que les indicarían cómo transitar:

«Las señales son de tres colores: "rojo", que indica que el paso está prohibido a los vehículos y permitido a los viandantes: "verde", que lo prohíbe a los transeúntes y lo permite a los coches, y "amarillo", que surge a la vez que toca un timbre y que sirve de avisador a peatones y carruajes» ${ }^{56}$.

«El color amarillo aparece cuando va a cambiarse el rojo por el verde, o viceversa, y anuncia a los peatones que deben apresurarse a cruzar -si luce el rojo - o disponerse para el cruce si brilla el verde. Esta señal amarilla durara de cuatro a seis segundos, e irá acompañada del sonido de unos timbres eléctricos. La duración de las señales roja o verde será de unos treinta a cincuenta segundos» ${ }^{57}$.

${ }^{54}$ La Libertad, 1 de agosto de 1925.

55 «Las señales luminosas para la circulación. Instrucciones para el público», en La Época, 13 de marzo de 1926; «La circulación en Madrid. Nuevos modos de regularla», en El Imparcial, 14 de marzo de 1926.

56 El Imparcial, 14 de marzo de 1926; ABC, 15 de marzo de 1926.

$57 A B C, 7$ de marzo de 1926. 
Madrid adoptó el sistema de tres colores que ha llegado a ser universal, aunque no lo era en los inicios de la difusión de los semáforos para controlar el tráfico viario, cuando la falta de uniformidad de los mismos era lo habitual, y no solo entre los utilizados en cada país, sino también entre las distintas ciudades de un mismo Estado ${ }^{58}$. Una vez efectuadas las correspondientes pruebas de funcionamiento, la Alcaldía dispuso que comenzaran a funcionar el 17 de marzo de 1926. La noche de su inauguración, el Alcalde, acompañado de Emilio Abarca y del jefe de la Guardia Municipal, recorrió los trayectos de las señales luminosas. Al haberse anunciado en los diarios la hora en que se pondrían en uso, numeroso público se dirigió a la calles de Alcalá y Gran Vía para ser testigos de la novedad. Una crónica publicada en el diario El Sol recogió el ambiente del momento:

«El público - una verdadera multitud llenando las aceras y los andenes centrales de los tranvías - seguía con curiosidad el funcionamiento del nuevo sistema, y acogía con risas o clamores de regocijo cualquier pequeña confusión entre los guardias y los conductores. Si al aparecer el color amarillo algún transeúnte audaz osaba bajar de la acera, mil voces le gritaban humorísticamente, advirtiéndole un peligro de muerte, y tenía que retroceder avergonzado, o seguir, aturdidísimo, hasta un andén salvador, entre el alborozo de la multitud» ${ }^{59}$

La inauguración de los modernos semáforos se convertía en espectáculo urbano en todas y cada una de las ciudades donde se instalaban. En Nueva York, según reportaba el New York Times, cientos de personas se habían reunido el 15 de marzo de 1922 para ver las pruebas de funcionamiento de las luces para regular el tráfico en dos céntricas avenidas ${ }^{60}$. Lo mismo sucedía en Madrid, donde las vacilaciones de los automovilistas ante la aparición de la luz ámbar, la inseguridad de los peatones al cruzar las calzadas, y las indicaciones y amonestaciones de los guardias a unos y otros, hicieron las delicias de los curiosos, y provocaron todo tipo de ingeniosidades y comentarios, recogidos en las planas de los diarios ${ }^{61}$. A finales de 1928, tras un viaje a Madrid donde estudió la organización

58 Buiter y Staal, 2006; McShane, 1999.

59 «El buen humor y la circulación», en $\mathrm{El} \mathrm{Sol,18}$ de marzo de 1926.

60 «Semaphore lights tested», en The New York Times, 16 de marzo de 1922.

${ }^{61}$ La Correspondencia Militar, 18 de marzo de 1926; «Inauguración de los discos luminosos», en El Sol, 18 de marzo de 1926. 
del tráfico, el Primer teniente de alcalde de Barcelona declaró que habría una nueva reglamentación de la circulación de vehículos y peatones, que incluiría la instalación de señales luminosas para regular el tráfico ${ }^{62}$. En agosto de 1929 comenzaron a funcionar, tras quedar instaladas en la plaza de Cataluña, Paseo de Gracia, las Ramblas, la Vía Layetana, calle de Cortes y plaza de España ${ }^{63}$. Estos semáforos eran prácticamente idénticos a los que funcionaban en Madrid: se adoptó el sistema de tres colores, y podían ser maniobrados de forma manual o automática según las necesidades circulatorias de cada momento ${ }^{64}$. Y tal y como se hizo en Madrid, en los primeros días de funcionamiento, los guardias urbanos siguieron dirigiendo el tráfico junto a los semáforos, ayudando al público a aprender y asimilar su funcionamiento, imprimiéndose y distribuyéndose también folletos con las nuevas reglas para circular que se imponían con la instalación de las señales ${ }^{65}$.

En los años treinta, se sumaron a la regulación semafórica del tráfico viario las ciudades de Valencia y San Sebastián, y otras, como Bilbao, estudiaron y elaboraron distintos proyectos de instalación de semáforos en los lugares de mayor intensidad circulatoria ${ }^{66}$. En junio de 1930, el delegado del Tráfico del Ayuntamiento de la capital del Turia anunció la adopción de un conjunto de medidas para solventar el problema circulatorio en la ciudad, entre las que se incluían la instalación de señales luminosas en el paseo de la Glorieta, plaza de la Reina y calles de la Paz y Comedias, y la señalización de pasos de peatones y de estacionamientos de vehículos públicos en distintos puntos urbanos ${ }^{67}$. Coincidiendo con la entrada en servicio de los nuevos semáforos, que funcionaban entre las 9 de la mañana y las 12 de la noche, el Ayuntamiento valenciano expresó su

62 Angel Marsá, «El tránsito urbano», en El Imparcial, 21 de diciembre de 1928.

63 Nota de la Delegación de Obras Públicas sobre la inauguración de las señales automáticas para ordenación del tráfico de vehículos y peatones, en La Vanguardia, 1 de agosto de 1929. La nota contiene explicaciones precisas sobre la interpretación por parte de los peatones y los automovilistas de los colores de los semáforos.

64 «La ordenación del tráfico por medio de señales luminosas en Barcelona», en El Pueblo, 2 de agosto de 1929.

${ }^{65}$ La Vanguardia, 21 de agosto de 1929.

66 AMB-BUA. Fondo Ayuntamiento de Bilbao, 131-M-1929. Propuestas e informes relativos a la necesidad de instalar señales luminosas de funcionamiento mecánico para regular el tráfico de la villa [...] 1929-1932.

${ }^{67}$ La Correspondencia de Valencia, 12 de junio de 1930; La Correspondencia de Valencia, 24 de junio de 1930. 
voluntad de instalar las señales luminosas que fueran precisas en el casco de la ciudad. San Sebastián, por su parte, se sumó a la regulación semafórica del tráfico con la instalación en agosto de 1933, de varios aparatos luminosos de tres colores, que se situaron en la calle Hernani y Avenida de la Libertad ${ }^{68}$.

Otras dos medidas adoptadas tempranamente en Madrid y Barcelona para mejorar el tráfico en ambas ciudades fueron el establecimiento del sistema de la dirección única en vez de en ambos sentidos en vías estrechas, y la adopción de la circulación rotatoria en las plazas. Ambas normas fueron ideadas para facilitar el flujo de tráfico, y habían mostrado su eficacia en ciudades europeas y americanas muy congestionadas. La dirección única funcionaba en Nueva York y en Boston desde 1905, y pronto fue adoptada por las ciudades europeas, donde a pesar de las reformas urbanas, seguían existiendo en sus áreas centrales calles estrechas por las que los cada vez más numerosos vehículos se desenvolvían con dificultad $^{69}$. En París, el primer ensayo para implantar este sistema circulatorio se remonta a 1908, y la hostilidad con la que fue recibida la medida por parte de los vecinos en los primeros momentos no evitó que se extendiera por la capital. En 1928, 165 calles de las 4.000 que tenía la ciudad eran de sentido único ${ }^{70}$. Aunque en sus inicios la norma se aplicaba solo en los días laborables y en las horas comprendidas entre las 8 de la mañana y las 8 de la tarde, por ser éste el periodo de mayor actividad circulatoria, finalmente, y una vez que los conductores se fueron habituando a ella, quedó establecida de forma permanente.

En el caso de Madrid y Barcelona, la supresión de la doble dirección en favor del sentido único se implantó de forma paulatina, comenzando por algunas calles de sus abigarrados cascos urbanos, y extendiéndose progresivamente por el resto del trazado urbano $^{71}$. En la capital de Es-

${ }^{68}$ La Voz de Guipúzcoa, 28 de julio de 1933; «Anoche se inauguraron las señales de la calle de Hernani», en La Voz de Guipúzcoa, 13 de agosto de 1933. Con motivo de inaugurarse las señales luminosas para el tráfico en San Sebastián, el ingeniero responsable de su instalación, Frank C. Chevalier, empleado de la Automatic Electric C. ${ }^{\circ}$ Ltd., ofreció dos charlas radiadas por Unión Radio San Sebastián, sobre su funcionamiento y sobre la organización del tráfico en la capital donostiarra. Véase Ondas, 9 de septiembre de 1933.

69 «Today's traffic regulations need detailed development», en The New York Times, 3 de noviembre de 1935 .

70 Conseil Municipal de Paris, 1928, pp 18-19.

${ }^{71}$ José Paz Maroto, «Los problemas de la circulación en las grandes ciudades y su resolución I y II», en Revista de Obras Públicas, 76, tomo I (1928), pp. 277-279 y pp. 292-294. 
paña la alcaldía dictó en 1922 dos bandos disponiendo la circulación en una sola dirección en 25 calles de la capital, colocándose carteles indicadores para avisar a los conductores. Del mismo modo que sucedió en París, la medida regía únicamente a determinadas horas del día ${ }^{72}$. Fue en octubre de 1924 cuando finalmente quedó establecida la dirección única en 21 calles de la ciudad, medida ratificada por el Reglamento de Tráfico de Madrid aprobado por la corporación municipal en $1926^{73}$. Ese mismo año se establecieron igualmente en Barcelona varias calles de dirección única para dar facilidad al tránsito rodado por disposición de la Alcaldía. El sistema del sentido único dio muy buenos resultados a juicio de los responsables del tráfico, por lo que siguió extendiéndose de modo paulatino por las calles del casco antiguo ${ }^{74}$. También Bilbao adoptó el sistema de vías de dirección única, implantándolo en las tortuosas calles del casco antiguo a mediados de los años veinte ${ }^{75}$.

El sistema de circulación rotatoria o giratoria en las plazas, era una nueva forma de circular que había sido implantada por primera vez en la plaza Columbus Circle de Nueva York en 1905, y dos años después en París, en la plaza del Arco del Triunfo ${ }^{76}$. Después de la Primera Guerra Mundial, se extendió a otras grandes ciudades y capitales europeas. En Londres, siempre reacios a importar las medidas que se adoptaban en el continente, el sistema giratorio se estableció en 1926 en Trafalgar Square,

72 Bando del marqués de Villabrágima regulando la circulación de peatones, carruajes y automóviles, de 18 de enero de 1922. Este bando establecía direcciones únicas para determinadas calles a partir de las 16 horas, y en otras entre las 9 y las 21 de la noche, norma que creaba, lógicamente, gran confusión entre los automovilistas. Un bando posterior del alcalde Conde de Valle Suchil, fijando la circulación de peatones y carruajes en las vías públicas, de 21 de octubre de 1922, estableció el sentido único ascendente en las 25 calles de la zona central de Madrid, sin distinción de horas.

73 Ayuntamiento de Madrid, 1926.

74 La Vanguardia, 7 de abril de 1926.

75 Expediente [...] solicitando la modificación del Reglamento provisional General de circulación y velocidad en esta villa en los artículos referentes a los horarios permitidos para el transporte de mercancías [...] así como en la articulación de las calles al tráfico rodado [...] Se aprueba el nuevo Reglamento sobre circulación y velocidades de los vehículos en la villa [...] A.H.F.B., sección Municipal, Bilbao Gobernación 0011/357; Expediente [...] formulando un proyecto de reforma del tráfico rodado en el Casco Viejo de la villa. A. H. F.B., sección Municipal, Bilbao Gobernación $0111 / 423$.

76 «Circulez!... Oui. Mais comment?. Lettre de M. Éno», en Le Matin, 24 de junio de 1910. 
Picadilly Circus y Hyde Park Corner ${ }^{77}$. En Madrid, al comenzar los años veinte, se empleaba el sistema circular en el tránsito rodado en la Puerta del Sol y en algunas otras plazas importantes, pero fue a partir de 1924, cuando gracias al trabajo de Emilio Abarca, director de la Oficina del Tráfico entre 1924 y 1931, se extendió a todas las plazas de la capital ${ }^{78}$. Esta medida fue sancionada por el Reglamento de Circulación Urbana e Interurbana de $1928^{79}$.

Se unificó igualmente en España el sentido de la marcha de los vehículos, una vez que Madrid - la última ciudad en España en implantar la circulación por la derecha- la adoptó en abril de $1924^{80}$. Con ello no solo se ponía fin a las confusiones de los conductores en las entradas y salidas de Madrid, sino también a la excepcionalidad de que dentro de un mismo país se circulara en ambas direcciones. Así lo recomendaba la Sociedad de Naciones y los expertos reunidos en el IV Congreso Internacional de Carreteras celebrado en Sevilla en mayo de 1923, quienes insistieron sobremanera en que al menos dentro de las fronteras de cada Estado rigiera una sola regla del tránsito ${ }^{81}$.

\section{Un hito en la gestión del tráfico urbano en España: el Primer Congreso Municipal de Circulación}

Al comenzar los años treinta, el aumento del problema circulatorio y la adopción de medidas para tratar sino de solucionarlo completamente si al menos de encauzarlo, hizo que las ciudades de Madrid y Barcelona estuvieran en disposición de erigirse en voces autorizadas sobre la materia, y guiar al resto del territorio urbano que poco a poco comenzaba a experimentar los problemas del tráfico urbano. El parque automovilístico español había alcanzado una envergadura notable (Gráfico 2) y ciudades como

77 «Gyratory traffic», en The Times, 16 de abril de 1926; «Gyratory traffic system. Trafalgar Square plan», en The Times, 26 de abril de 1926; «London traffic control. Picadilly Circus experiment. Roundabout system», en The Times, 27 de julio de 1926; «The gyratory system», en The Times, 16 de agosto de 1926.

78 Abarca, 1927.

79 Publicado en la Gaceta de Madrid de 5 de agosto de 1928.

${ }^{80}$ La norma, promulgada mediante un bando del Gobernador Civil de Madrid, entró en vigor el 10 de abril de 1924 .

${ }^{81}$ Conclusiones del IV Congreso Internacional de Carreteras de Sevilla reproducidas en Revista de Obras Públicas, 2382 (1923), pp. 41-43. 
Zaragoza, San Sebastián, Valencia, etc., habían comenzado a aplicar algunas de las medidas que funcionaban ya en Madrid y en Barcelona. Al ir en aumento el número de ayuntamientos españoles enfrentados a los problemas de la circulación urbana, se entiende la positiva y favorable respuesta a la invitación cursada a finales de 1932 a todos los municipios españoles mayores de 20.000 habitantes para participar en el I Congreso Municipal de Circulación, que habría de celebrarse en Madrid en los primeros días del siguiente año ${ }^{82}$. La iniciativa para la celebración del evento partió de quien entonces ocupaba el cargo de concejal delegado del Tráfico en el Ayuntamiento de la capital de España, Fabián Talanquer.

En 1932, el concejal se dirigió al Alcalde informándole de la celebración en marzo del año anterior en Ginebra de la Conferencia europea sobre la circulación por carretera, en la que se habían tomado acuerdos de gran importancia sobre la cuestión, y que estaban próximos a implantarse en las principales urbes europeas ${ }^{83}$. Aunque no habían sido notificados oficialmente al Ayuntamiento de Madrid, Talanquer consideraba que España no podía quedar al margen de tales acuerdos y propuso celebrar un congreso de municipios españoles «a fin de tratar del acoplamiento de aquellas disposiciones a las actuales así como a los Reglamentos de Circulación con modificaciones de las señales reguladoras del tránsito» ${ }^{84}$. La alcaldía acogió con entusiasmo la idea, y en noviembre de ese mismo año acordó la celebración de la conferencia, cuyo objetivo sería lograr regularizar y unificar las normas de circulación, así como alcanzar unas bases comunes para todo el territorio nacional de toda la legislación y normas que regían el tráfico, señalando que la cuestión era de la mayor importancia, «máxime tratándose de un país de tan gran porvenir turístico como el nuestro» ${ }^{85}$.

Quedó previsto que el Congreso se celebraría en Madrid en los primeros días de enero de 1933. Finalmente, la asamblea transcurrió entre el 9 y el 15 de aquel mes, y a ella concurrieron 33 ayuntamientos españoles,

${ }^{82}$ Las principales localidades del país enviaron representantes, otras delegaron en sus representantes a Cortes u otras personalidades. $A B C, 4$ de enero de 1933.

${ }^{83} \mathrm{La}$ Conferencia europea sobre la circulación por carretera se reunió en Ginebra entre los días 16 al 31 de marzo, convocada por el Consejo de la Sociedad de Naciones. La Conferencia adoptó dos convenios, uno sobre la unificación de las señales en las carreteras, y otro sobre el régimen fiscal aplicable a los vehículos automóviles extranjeros. Boletín Mensual de la Sociedad de las Naciones, . $^{\circ} 3$ (1-31 de marzo de 1931).

84 A.V.M., Secretaría, expediente 29-368-81.

85 A.V.M., Secretaría, expediente 29-368-81. 
estando otros muchos representados mediante delegación ${ }^{86}$. Se invitó asimismo a todas aquellas entidades extra municipales cuyo asesoramiento pudiera ser útil en el Congreso, participando un total de 33. Entre ellas, distintas asociaciones patronales y obreras del sector del transporte, como la Sección de Obreros del Tranvía, la Cámara Española del Automóvil, la Asociación General de Agentes de Transportes, la Sociedad de Obreros del Transporte o la Cámara Oficial del Transporte Mecánico. Se sumaron igualmente algunas grandes empresas del transporte público tanto local como nacional, tales como los Ferrocarriles M.Z.A., los Ferrocarriles del Norte de España o la Compañía de Tranvías de Madrid. Finalmente, otras entidades de distinto carácter interesadas en las cuestiones relacionadas con los problemas del tráfico urbano, como el Touring Club, la Jefatura de Obras Públicas de Madrid o el Instituto Psicotécnico de Madrid. Estas

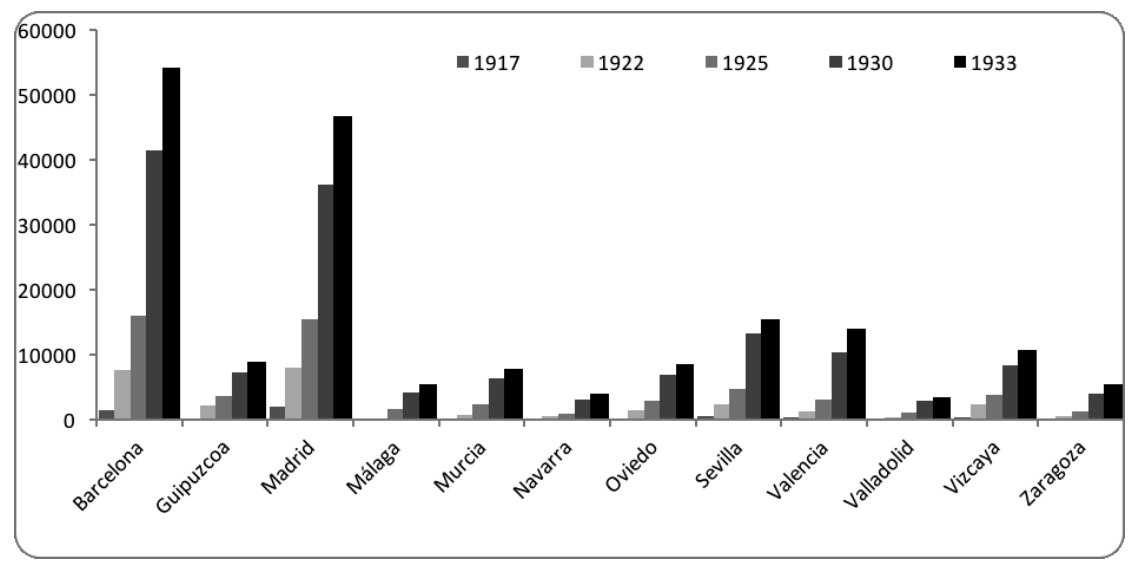

Gráfico 2

Evolución de la matrícula de automóviles en las principales provincias españolas en los años indicados. Los datos de 1917 corresponden a la capital de la provincia y no al total provincial.

Fuente: Anuarios estadísticos de España, años 1917, 1921-22, 1930 y 1934. Instituto Nacional de Estadística

86 «El Congreso Municipal de Circulación», en La Voz, 9 de enero de 1933; «El Congreso de Circulación», en El Sol, 12 de enero de 1933; «El Congreso Municipal de Circulación», en Heraldo de Madrid, 13 de enero de 1933. 
instituciones colaboraron de forma activa en el desarrollo del Congreso, presentando algunas ponencias para su debate, enmiendas a los temas tratados o simplemente divulgando las conclusiones y acuerdos tomados en el Congreso a través de sus órganos de expresión ${ }^{87}$.

A lo largo de una semana, las distintas comisiones organizadas trabajaron sobre un total de 16 temas, que abarcaban todos los aspectos relacionados con el tráfico en las ciudades, incluyendo, entre otros, los reglamentos y estadísticas de circulación, la formación de los conductores de servicio público y de los agentes de circulación, la matriculación de vehículos, las concesiones de líneas de tranvías y ferrocarriles subterráneos, etc., etc., siendo el tema dedicado a la regulación del tráfico peatonal el que suscitó los debates más acalorados ${ }^{88}$. Como base para las discusiones, los ayuntamientos de Madrid y Barcelona presentaron sendas ponencias que, aunque de muy distinto contenido, contenían las líneas maestras y las cuestiones que debían ser estudiadas en el Congreso ${ }^{89}$. Ambos textos eran también una afirmación del liderazgo de las dos ciudades en lo referente a la gestión del tráfico urbano. Al finalizar el evento, los representantes de los Ayuntamientos participantes se comprometieron a presentar a sus respectivos municipios los acuerdos aprobados, para que lo antes posible los pusieran en vigor. Se decidió igualmente elevar al Gobierno las conclusiones que tenían un carácter nacional, dirigiéndose cada Ayuntamiento directamente por instancia a la Presidencia del Consejo de Ministros, solicitando su efectividad legal ${ }^{90}$.

La importancia del Congreso reside, ante todo, en el hecho de haber puesto en primer plano la necesidad de que en toda España se unificara la

${ }^{87}$ Revista de Organización Científica del Trabajo, 19 (marzo de 1933), pp. 366-387; Ingeniería y construcción, 122 (febrero de 1933); Primer Congreso Municipal de Circulación..., 1933.

${ }^{88}$ Temas tratados en el I Congreso Municipal de la Circulación sobre los que se adoptaron acuerdos: I. Reglamentos, II. Proyectos planimétricos, III. Circulación en las calles, IV. Señales en vías públicas, V. Emplazamiento de estaciones de líneas regulares de autobuses, VI. Intervención o fiscalización en determinados servicios, VII. Licencias municipales y reconocimientos de vehículos, VIII. Conductores de servicio público, IX. Estadísticas de circulación, X. Agentes de circulación, XI. Peatones, XII. Creación Comité o Junta permanente de enlace y asesoramiento, XIII. Infracciones y procedimientos, XIV. Señales, XV. Matrículas, XVI. Transportes. A.V.M., Secretaría, expediente 29-59-48.

89 Primer congreso municipal de circulación..., 1933; Primer Congreso Municipal de Circulación: Ponencia formulada..., 1933.

90 A.V.M., Secretaría, expediente 29-59-48. 
reglamentación de la circulación, incluyendo todo lo referente a señales del tráfico. Se insistió, por ejemplo, en la necesidad de adoptar un sistema único de señales circulatorias - luminosas u opacas - que debían ser las que habían sido aprobadas en la ya citada Conferencia de la carretera de Ginebra de 1931, organizada a instancias de la Sociedad de Naciones. Es decir, se imponía la recomendación de seguir los criterios marcados por los organismos internacionales, insertando así a España en el concierto de las naciones occidentales. Finalmente, podemos considerar el I Congreso Municipal de Circulación, el acto fundacional en el estudio y aplicación - de manera coordinada y con ámbito nacional-, de normas para gestionar y mejorar el tráfico urbano, en un momento en el que esta cuestión había adquirido un lugar preeminente en las agendas locales.

\section{Conclusiones}

El denominado en la época «problema de la circulación» despuntó en las grandes ciudades españolas en los primeros años del siglo XX, extendiéndose durante los años veinte y treinta por el resto de la trama urbana del país. Este nuevo problema urbano surgió como consecuencia, por una parte, del crecimiento exponencial del número de vehículos y peatones en las calles, y, por otra, de la existencia de trazados urbanos, particularmente las áreas centrales de las ciudades, incapaces de acoger las nuevas corrientes circulatorias. Al comenzar los años treinta, los embotellamientos y la congestión circulatoria eran una realidad cotidiana en capitales como Madrid y Barcelona, que se sumaron así a un fenómeno que adquirió ya en el primer tercio del siglo XX, una dimensión global.

Los ayuntamientos de las principales urbes españolas acometieron el problema implementando una serie de medidas con las que tomó carta de naturaleza en España la gestión del tráfico, algunas de las cuales han sido analizadas en este artículo. El objetivo de todas ellas era mejorar la circulación en el interior de las ciudades. Los resultados obtenidos estuvieron lejos de ser los anhelados por los responsables de articularlas, pero antes que un fracaso estos primeros esfuerzos deben ser considerados, por el contrario, como un éxito limitado. Hay que considerar a este respecto la crónica escasez de recursos materiales y personales de las corporaciones locales en aquellos momentos, las iniciales y comprensibles resistencias de conductores y transeúntes ante la proliferación de normas circulatorias cada vez más restrictivas y, ante todo, el imparable crecimiento del nú- 
mero de vehículos en las calles ${ }^{91}$, que hacían que el problema no pudiera solucionarse de una forma definitiva dado su carácter cambiante.

El aumento y complicación del tráfico y su regulación, como consecuencia del crecimiento urbano y la multiplicación de los medios de transporte, en particular de los vehículos de motor, en las principales ciudades durante la Segunda República fue una expresión de la profunda transformación que la sociedad urbana española registró durante el primer tercio del siglo XX. Una transformación que alteró la vida urbana, cambió los estilos y formas de vida, y constituyó una de las manifestaciones más relevantes de la irrupción de la modernidad en la España urbana de los años treinta ${ }^{92}$.

\section{Fuentes}

ARChIVO DE VILLA DE MAdRID (A.V.M.).

Archivo Municipal de Bilbao-Bilboko Udal Artixboa (AMB-BUA).

Archivo Histórico Foral de Bizkaia-Bizkaiko Foru Agiritegi HistorikoA (A.H.F.B.).

BiblioteCa Digital HispáNica.

BiblioteCA NACIONAL DE EsPaÑa.

Biblioteca Virtual de Prensa Histórica, Ministerio de Cultura.

HEMEROTECA DE $A B C$.

HEMEROTECA DE LA VANGUARDIA.

HEMEROTECA Municipal DE MADRID.

LABORATORIO DE MicROFILMACIÓn y DigitalizaCión, Departamento de Historia Contemporánea, Universidad del País Vasco.

\section{Bibliografía}

ABARCA, Emilio, Exposición que acompaño al Reglamento del Tráfico, Imprenta Municipal, Madrid, 1926.

AbARCA, Emilio, El problema de la circulación, Publicaciones de la Unión de Municipios Españoles, Madrid, 1927.

91 Otra línea de investigación en la que actualmente estoy trabajando, y que complementa el estudio de la movilidad mecánica al que se dedica este artículo, es la organización y regulación del tráfico peatonal en las ciudades españolas durante el primer tercio del siglo XX.

92 Beascoechea y Otero, 2015. 
AyUnTAMIENTO DE MADRID, Estudio de la circulación de carruajes y peatones que, a juicio del segundo Jefe de Policía urbana, D. Emilio Abarca Millán, debe implantarse en Madrid para la mejor organización de los mismos, Madrid, Imprenta Municipal, 1924.

AyUnTAMIENTO DE MADRID, Reglamento para el establecimiento de "garages», talleres e instalación de depósitos subterráneos de gasolina, tanto en el interior de aquéllos como en la vía pública, Imprenta Municipal, Madrid, 1925.

Ayuntamiento DE MAdrid, Reglamento del Tráfico, Imprenta Municipal, Madrid, 1926.

AyuntAmiento De MAdRID, Información sobre la ciudad. Año 1929: Memoria. Madrid, s. e., s. d. [1929].

BAKER, Edward, Madrid Cosmopolita. La Gran Vía, 1910-1936, Madrid, Marcial Pons, 2009.

BeAscoecheA, José María y Otero, Luis Enrique (eds.): Las nuevas clases medias urbanas. Transformación y cambio social en España, 1900-1936, La Catarata, Madrid, 2015.

Buiter, Hans y STAaL, Peter-Eloy, «City lights. Regulated Streets and the Evolution of Traffic Lights in the Netherlands, 1920-1940», The Journal of Transport History, 27, 2, 2006, pp. 1-20.

CANo, Tomás, El régimen jurídico-administrativo del tráfico. Bases históricas y constitucionales, técnicas de intervención y sanciones, Civitas, Madrid, 1999.

CONSEIL Municipal DE PARIS, Rapport au nom de la $2 e$ Commission sur la circulation générale des voitures et des piétons à Paris présenté para M. Emile Massard, Paris, 1910.

De Miguel, Santiago, Madrid, sinfonía de una metrópoli europea, 1860-1936, La Catarata, Madrid, 2016.

Flonneau, Mathieu, L'Automobile à la conquête de Paris. Chroniques illustrées, Presses de l'école nationale des Ponts et chaussées, Paris, 2003.

FlonNEAU, Mathieu, «City infrastructures and city dwellers. Accomodating the Automobile in Twentieth-Century Paris», The Journal of Transport History, 27, 1, 2006, pp. 93-114.

GonZÁLEZ, M. ${ }^{a}$ Pilar, El transporte configurador del desarrollo metropolitano de Madrid. Del inicio del ferrocarril al metro ligero, siglo y medio de historia, Separata de Anales del Instituto de Estudios Madrileños, Tomo XLVI, CSIC, Madrid, 2006.

GuTIÉRREZ, Diego, Tranvías de Madrid, La Librería, Madrid, 2001.

LópeZ, Antonio, Los transportes urbanos de Madrid, CSIC, Madrid, 1983.

LóPEZ, Carlos, Tranvías de Madrid, Aldaba, Madrid, 1993.

LUZ ÁMBAR. HISTORIA GRÁFICA DE 75 AÑOS AL SERVICIO DE LA CIUDAD, La Librería, Madrid, 2007.

McSHANE, Clay, «The origins and globalization of traffic control signals», Journal of Urban History, n. 3 , 1999, pp. 379-404. 
La aparición del «problema de la circulación» y los orígenes de la gestión...

Memoria de Circulación por José de la Hoz Muñoz. Jefe accidental de la COMPAÑ́́a DE CIRCULACIÓN. Ayuntamiento de Madrid. Año 1932.

PAZ, José, Time is money. El problema de la circulación. Memoria premiada por el excelentísimo Ayuntamiento de Madrid en el concurso celebrado el año 1932, Artes Gráficas Municipales, Madrid, 1933.

Plan General de eXtensión. Memoria, Imprenta Municipal, Madrid, 1926.

Pooley, Colin G. y Turnbull, Jean, «Coping with congestion: responses to urban traffic problems in British cities c.1920-1960», Journal of Historical Geography. 31, 2005, pp. 78-93.

PRIMER Congreso Municipal de CiRCULACIÓN (celebrado en Madrid durante los días 9 al 15 de enero de 1933), Asociación General de Transportes por Vía Férrea, Madrid, 1933.

Real Automóvil Club de EsPaña, Emplazamiento de surtidores públicos de gasolina, Madrid, Gráficas Ruiz Ferry, 1928.

RodríGUEZ, Nuria, La capital de un sueño. Madrid en el primer tercio del siglo XX, Centro de Estudios Políticos y Constitucionales, Madrid, 2015.

RoDRíGUEZ, Nuria, «La invasión de los bárbaros del anuncio. Una historia de la publicidad exterior en Madrid, 1900-1936», Revista internacional de Historia de la Comunicación, I, 7, 2016, pp. 42-66.

Weinstein, Asha, «Congestion as a Cultural Construct. The "Congestion Evil" in Boston in the 1890s and 1920s», The Journal of Transport History, 27, 2, 2006, pp. 97-115.

WINTER, James, London's Teeming Streets 1830-1914, Routledge, London, 1993.

\section{Agradecimientos}

Este artículo ha sido posible por la concesión de un contrato postdoctoral «Juan de la Cierva» (Ref.: FJCI-2014-20553), y del proyecto de investigación «La sociedad urbana en la España del primer tercio del siglo XX. Madrid y Bilbao, vanguardia de la modernidad, 1900-1936», HAR2015-65134-C2-2-P (MINECO/FEDER). Quiero agradecer a los profesores Pedro A. Novo López y Luis E. Otero Carvajal la lectura del borrador inicial del texto y los comentarios y sugerencias al mismo, así como las observaciones de los revisores anónimos, que han contribuido a mejorarlo. 


\section{Datos de la autora}

Nuria Rodríguez Martín es Licenciada en Ciencias de la Información y en Historia y Doctora en Historia por la Universidad Complutense de Madrid. En la actualidad es Investigadora "Juan de la Cierva" adscrita a la Universidad del País Vasco. Ha sido Lectora de Español en la Universidad Paris-Sorbonne (Paris IV) entre 2013 y 2015 y ha completado su formación doctoral en las Universidades de Oxford, Cambridge y Edimburgo. Miembro del grupo de investigación de la UPV/ EHU "Demografía Histórica e Historia Urbana», es autora, entre otras publicaciones, de la obra La capital de un sueño. Madrid en el primer tercio del siglo XX (Centro de Estudios Políticos y Constitucionales, 2015), galardonada en los XIX Premios Nacionales de Edición Universitaria como la mejor monografía en el área de Arte y Humanidades (2016). 